\title{
RELIGIÃO, CONFLITO E RECONHECIMENTO: CENÁRIOS EUROPEUS
}

\section{RELIGION, CONFLICT AND RECOGNITION: EUROPEAN SCENARIOS}

\begin{abstract}
Alfredo Teixeira ${ }^{1}$
\section{Resumo}

Neste texto analisam-se alguns cenários europeus marcados por diferentes lógicas de conflito. Dá-se uma particular atenção a diferentes dinâmicas sociais, que visam garantir a visibilidade das identidades religiosas em contextos de crescente diferenciação religiosa. Nesta nova paisagem religiosa, o conflito é, frequentemente, uma via de reconhecimento. A visibilidade da diferença religiosa mobiliza, nas democracias liberais, estratégias de discriminação positiva. No entanto, pelo menos em parte, esses usos sociais do conflito dão conta de um movimento de mudança: na procura de reconhecimento, ganha protagonismo a afirmação da autonomia individual, em detrimento da reivindicação dos direitos das instituições religiosas.
\end{abstract}

Palavras-Chave: Religião; Conflito; Reconhecimento; Laicidade.

\section{Abstract}

This paper examines some European scenarios affected by various logics of conflict. Particular attention has been given to diverse social dynamics, which aim at ensuring the visibility of religious identities in contexts of growing religious diversity. In this new religious landscape, conflict is often a way of recognition. In liberal democracies, the visibility of religious difference mobilizes strategies of positive discrimination. However, at least in part, these social uses of conflict indicate a process of change: in the search for recognizing, the affirmation of individual autonomy is given prominence, in the place of claiming the rights of religious institutions.

Keywords: Religion; Conflict; Recognition; Laicity.

\section{Introdução}

Este breve ensaio proporá algumas hipóteses interpretativas para as dinâmicas sociais que constroem as novas formas de visibilidade do religioso na cena pública europeia. Num primeiro momento, procura-se mapear diferentes planos de expressão do conflito, no tocante à afirmação pública da identidade religiosa. Num segundo momento, ensaia-se a demonstração de que está em curso uma ampla remodelação no que toca aos quadros sociais de relação das instituições e agentes em jogo. Nos modelos de laicidade mais convencionais, estes problemas são pensados no plano da negociação entre o Estado e as identidades

\footnotetext{
1 Doutor em Antropologia Política. Professor na Universidade Católica Portuguesa. Colaborador no Programa de Pós-Graduação em História e Cultura das Religiões da Universidade de Lisboa.

E-mail: alfredo.teixeira@ft.lisboa.ucp.pt ORCID: https://orcid.org/0000-0002-8946-5538
} 
religiosas na sua expressão coletiva. No entanto, como se sublinhará, é também a partir do imperativo da liberdade de consciência e da narrativa da emancipação individual que o religioso se recompõe na cena pública, contexto que afeta o funcionamento dos dispositivos de medição política historicamente construídos.

Este itinerário permitirá colocar a hipótese de que o núcleo das tensões próprias da modernidade europeia não se encontre, em primeira instância (ou pleno menos, apenas), nessa oposição entre religião e política, mas na cesura entre a experiência coletiva e a afirmação da autonomia do indivíduo. Essa descontinuidade pode descrever-se num arco plural de categorias políticas: holismo/individualismo, comunidade/sociedade, etnicidade/cidadania, entre outras.

\section{As lógicas do conflito: dinâmicas e contextos sociais}

Numa primeira via, os conflitos desenham-se a partir da lógica das estratégias e grupos de interesse, com particular expressão nas relações entre organizações religiosas e poderes públicos. Esses conflitos dizem respeito, recorrentemente, às diversas formas de visibilidade religiosa e de reconhecimento institucional. Veja-se o caso das reivindicações e negociações relativas à construção de lugares de culto ou à construção de edifícios que possam veículos de transmissão da memória religiosa (monumentos, museus, centros de interpretação, etc.). No que concerne aos locais de culto, as negociações mobilizam particularmente os agentes da política municipal ou regional. Em Lisboa, a zona do Martim Moniz, foi palco da implementação de uma política local de mediação, tendo em conta a diversidade religiosa que aí se condensa. José Mapril deu conta, na sua investigação, do papel que a identificação ou edificação de locais de culto pode ter nas dinâmicas de remodelação das identidades - no caso, a recomposição do islão bangladechiano, num quadro de transnacionalidade (Mapril, 2012, 197-229). Por vezes, as próprias comunidades religiosas se tornam contextos favoráveis de mediação. Na Área Metropolitana de Lisboa, a Igreja Kimbanquista foi realojada na Quinta da Fonte, no município de Loures, por altura das obras da Ponte Vasco da Gama. Aí Igreja ganhou algum protagonismo no quadro das políticas implementadas pelas autoridades municipais de Loures - recorde-se que a Câmara Municipal de Loures tinha criado, em 1993, o «Gabinete de Assuntos Religiosos e Sociais Específicos». Naquele contexto, aquela Igreja teve um reconhecido 
papel de moderação e mediação, ajudando a ultrapassar cenários de conflituosidade ética.

Estes contextos são, frequentemente, o palco de processos de politização das questões religiosas. Tomando o caso da discussão pública acerca do uso de signos religiosos nos estabelecimentos de ensino, em França, em 2003-2004, a politóloga F. Lorcerie mostrou como esse caso foi fortemente mobilizador dos diferentes atores e instituições políticas, tornando-se um lugar de reconfiguração da própria cena política institucional e de renovação dos discursos acerca da identidade nacional (Lorcerie, 2013, 15-21).

Este é o domínio em que importa testar a distinção entre conflitos sociais divisíveis e indivisíveis, proposta por Albert Hirschman (1994). Os primeiros, que suscitam mecanismos de negociação diversos, são típicos de uma sociedade de mercado, sociedade em que o domínio social se divide em classes, setores ou regiões. Os segundos - de natureza religiosa, étnica, linguística ou moral - têm um carácter inegociável, porque dizem respeito a objetos não divisíveis e, por isso, diminuem o intervalo do compromisso. Na medida em que este tipo de conflito pode estruturar-se a partir da vinculação incondicional a uma mundividência, podem ser necessários outros recursos políticos. A opinião pública tende a ver este tipo de conflito como o mais perigoso para as sociedades democráticas. No entanto, esta distinção, não deve ser absolutizada, mesmo se ela tem alguma força analítica, sob o ponto de vista teórico. Um olhar socioantropológico multissituado depressa descobre que a relação entre as mundividências e a ação dos indivíduos se descreve por laços complexos e frágeis. São abundantes as situações em que os indivíduos, partilhando uma mesma visão do mundo, tomam decisões contrastantes, agem de forma vincadamente diferente (Lamine, 2013, 217). Por outro lado, por vezes, uma determinada afirmação de interesse é tomada como dizendo respeito a uma comunidade de pertença religiosa, quando, de facto, diz respeito a um conjunto de atores dentro desse grupo. A análise destas situações de conflito exige o conhecimento do pluralismo interno.

Os conflitos podem ser analisados, também, numa segunda via, a partir da observação das fronteiras entre os grupos. A distinção entre «nós» e os «outros» está no cerne dos processos de construção social. Quanto se analisam as dinâmicas de conflito nas sociedades, é útil perceber que tipo de fronteira está em causa. 
Há fronteiras sociais que se objetivam nas formas desiguais de acesso a diferentes bens, materiais e imateriais. Mas há também fronteiras simbólicas, constituídas a partir das representações usadas para qualificar e diferenciar objetos, pessoas, tempos e espaços. O uso da memória religiosa para a construção de fronteiras nacionais tem amplas variações. Bail (2008), num estudo comparativo, mostrou como esse recurso tem tido uma relação direta com os fluxos de imigração que favorecem a constituição, no território, de grupos com memórias religiosas distintas. A emergência do diverso pode suscitar a ativação de diferentes formas de rememoração e reidentificação religiosas.

Em algumas das formas de maior impacto, a gramática do conflito de valores é o principal recurso para classificar um conflito de étnico ou religioso. Isso pode acontecer tanto no contexto de populações com características maioritárias, como em contextos de identidades minoritárias. Os discursos acerca da incompatibilidade entre sistemas de valor são um dos substratos dos processos de contra-identificação - ou seja, a representação de si através da construção de uma imagem dos «outros». Françoise Lorcerie, num estudo acerca dos usos do Islão em França, procurou mostrar como a lei de 2004, sobre os sinais religiosos, se definiu num quadro argumentativo próximo da lógica do «pânico moral». As amplas discussões sobre o uso do véu integral revelavam-se desproporcionais quando considerado o escasso número de pessoas envolvidas, no território francês. Mas essa desproporção pode encontrar-se também em contextos minoritários. A antropóloga Clara Mafra (2002, 29-59) mostrou como, no início da sua implantação em Portugal, os pregadores da IURD sustentavam a ideia de perseguição em termos notoriamente desmesurados, tendo em conta os factos sociais.

Deve sublinhar-se, também, que estas fronteiras entre grupos são móveis (Lamine, 2013, 221). Por exemplo, os estudos realizados nos anos 90 sobre as comunidades de imigrantes, oriundos de espaços islamizados, mostraram que diversas Igrejas cristãs tiveram um importante papel na integração dessas populações. Nesse contexto social, o Islão não era visto como corrente no tecido plural da oferta de bens religiosos. Com frequência, os imigrantes muçulmanos eram integrados nas redes de cuidado social, onde as Igrejas têm uma particular presença - sobretudo em situações onde não era ainda possível reconstituir as 
civilidades e solidariedades islâmicas (Galembert, 2003). Num outro contexto, quando numa votação de iniciativa popular, realizada no dia 29 de novembro de 2009, a população helvética foi consultada acerca da construção de novos minaretes, os cenários apresentavam novos contornos. O estudo de Sébastien Fath (2013) mostrou que a tendência para a limitação de novas construções estava fortemente presente nos votantes pertencentes a lgrejas evangélicas, mesmo se as suas lideranças e outras instituições, no espaço público, manifestaram posições que não acompanhavam essa tendência. Tome-se ainda outro exemplo. Um estudo de AnneSophie Lamine $(2004,249)$ a socióloga refere-se ao depoimento de um padre católico que identificava os termos de uma ampla remodelação das fronteiras, no catolicismo francês, entre os anos 60 e o início do século XXI. Anteriormente, para o católico, a figura do «outro» era preenchida pelo ateu. Agora, na sua perspetiva, o «outro» é o hiper-religioso, aquele que se representa a partir de uma identidade religiosa forte, contrastante com a imagem de um catolicismo discreto herdada dos anos 60. O padre católico observava como, por exemplo, pode ser difícil encontrar um jovem católico com a competência necessária ao debate, com o seu colega muçulmano, acerca da figura de Jesus como profeta.

Numa terceira via interpretativa, os conflitos podem ser lidos como forma de interação, com resultados construtivos nos processos de socialização e de construção da coesão social. Uma parte importante destes novos cenários resulta de recomposições na escala das identidades e poderes locais e não já no plano convencional das formas de regulação do Estado central. Os problemas relacionados com locais de culto, cemitérios, reconhecimento de interlocutores, dietas e outras civilidades em estabelecimentos públicos põem problemas novos, na escala do poder local, na Europa. Alguns municípios, no quadro dos seus programas de inovação institucional, responderam a estes novos contextos com a criação de instâncias de mediação especificamente vocacionadas para a intervenção na área do pluralismo religioso. Em muitas destas circunstâncias, os conflitos podem desenvolver um ambiente favorável ao conhecimento e à implementação de processos socializantes. Por um lado, a presença de autoridades locais nos grandes acontecimentos das comunidades de pertença religiosa tornou-se mais frequente. Por outro, os próprios poderes locais criam dispositivos de aproximação que visam favorecer a 
convivência inter-religiosa. Trata-se de um terreno definido pelas práticas da negociação. Mas essas práticas necessitam de novas formas de conhecimento e reconhecimento (Frégosi; Willaime, 2001; Lamine, 2004; Donnet, 2013).

Em estudos recentes sobre o pluralismo religioso em meio prisional, mostravase como, em alguns contextos nacionais, se tornou possível ter uma política de alojamento que tivesse em conta a diversidade religiosa - como antes já tinha sido possível, a partir de critérios de outra natureza, como o de fumador ou não-fumador. Neste contexto, a autêntica neutralidade do Estado pode passar, não pela invisibilidade do religioso na vida prisional, mas pelo seu reconhecimento, exigindo novas competências e novas formas de organização, que melhorem as condições da vida quotidiana e moderem as possibilidades de conflito (Sarg, 2013; Béraud, Galembert et Ristaing, 2016).

\section{A laicidade face à narrativa da indivíduo autónomo}

Pode a história política da religião no Ocidente europeu moderno desenhar-se a partir do modelo clássico Igreja-Estado? A regulação dos conflitos tem estado bastante dependente de modalidades de negociação que exigem das comunidades de pertença religiosa dispositivos de representação coletiva, nem sempre fáceis de implementar. Mas os dinamismos sociais são também legíveis a partir de um vaivém simbólico entre os projetos de uma salvação pela via da construção coletiva e as escolhas de uma salvação pela conversão individual. Neste modelo de análise, o religioso e o político não se opõem em si - essa oposição decorre do impacto das descontinuidades entre o social e o individual. Os processos de individualização do sentido e de autovalidação dos projetos de orientação existencial afetam os recursos disponíveis para a construção do laço social, com um assinalável impacto tanto na socialização política como na comunitarização religiosa. ${ }^{2}$ Os cruzamentos entre 0 liberalismo da conversão individual e o anúncio de uma ordem social redentora não

\footnotetext{
2 No quadro destas amplas remodelações, as instituições religiosas parecem apresentar uma maior plasticidade, quanto às formas de comunitarização dos crentes, do que as instituições do político (Hervieu-Léger, 2001, 141-179).
} 
pararam de se suceder. Alguns diagnósticos veem, assim, a atual crise do político como uma espécie de sucedâneo da anterior crise do religioso. Não serão essas duas crises, faces de uma mesma tensão que habita o dinamismo da modernidade europeia? O que é característico das sociedades modernas não é a constituição de uma simetria entre Estado e Igreja, atribuindo-Ihes, respetivamente, a esfera do temporal e a esfera do espiritual. As tensões mais nucleares dão conta de uma outra diferenciação ou separação: o universo do social e o pluriverso do individual. ${ }^{3}$

A laicidade, como narrativa política, pretende proteger a ordem pública, mas de igual forma a liberdade de consciência individual. A lei e a liberdade de consciência implicam-se de forma paradoxal. A lei, em democracia, exige o desenvolvimento das competências que mobilizam o consenso dos cidadãos. Mas também pode dizer-se que não há forma de garantir a liberdade individual sem um Direito na sociedade. Paradoxalmente, a lei constrange os indivíduos e, ao mesmo tempo, garante a sua liberdade de consciência. A falha que impede a total coincidência entre uma ordem coletiva e a individualidade irredutível pode ser o lugar das mais nucleares tensões modernas. Assim, é necessário trabalhar sobre a hipótese de que a separação que melhor descreve o núcleo da política do simbólico na modernidade não se encontra na antinomia religião/política, mas na dissociação entre a esfera do sujeito (pessoal, interpessoal, afetivo, ético) e o mundo da objetividade coletiva (económico, político e social). ${ }^{4}$

A narrativa da autonomia do sujeito moderno - a mesma que antes justificou as teorias do fim da religião - pode explicar agora, afinal, as recomposições do religioso na cena pública. O reinvestimento nas funções sociais do religioso alimentase dos valores da liberdade individual, em particular, a liberdade de consciência. Nos debates e confrontos suscitados por determinadas intervenções normativas, que visam diminuir o impacte das identidades religiosas mais musculadas, em nome de um comum ideal de cidadania, os «religiosos» criticam a intervenção estatal a partir da reivindicação de liberdade individual - as suas reivindicações não se apresentam, na cena pública, sob o imperativo de uma logocracia revelada ou sob a urgência da

\footnotetext{
3 Cf. Blaquart, 2010, 61-63; Willaime, 2004, 202-235; Hervieu-Léger, 1999, 157-200; Dieckhoff, 1997, 317-322; Michel, 1994, 111-132.

${ }^{4}$ Cf. Blaquart, 2010, 65; Willaime, 2004, 235-249; Pace, 1997, 339-346.
} 
perpetuação de uma tradição. O religioso recompõe-se, assim, no âmago de uma narrativa ultramoderna. ${ }^{5}$

\section{Observações conclusivas}

Não se deve perder de vista que os modelos de laicidade estão muito dependentes das forças em jogo num determinado espaço social. Nas últimas décadas, tornou-se necessário ter em conta, ainda, que é a partir do imperativo da liberdade de consciência e da narrativa da emancipação individual que o religioso se recompõe na cena pública. $\mathrm{O}$ «último» Habermas pode documentar esta rotação de perspetiva, ele que pugna, na linha da Escola de Frankfurt, por uma modernidade reformista. A sua teoria da religião foi muito influente em alguns dos modelos de interpretação sociológica da secularização europeia, nos anos 80 . A sua ascendência weberiana é clara, tendo em conta a importância atribuída aos processos de racionalização das mundividências (cf. 1981, I-II). Tal como outros «pais» da teoria social da secularização, o «último» Habermas reorientou as suas afirmações acerca da relevância social da religião, tendo em conta as transformações que conhecemos no curso das múltiplas modernidades. ${ }^{6}$ Numa das suas últimas obras sobre política e religião, regressou ao problema que nos ocupa a partir de uma outra perspetiva. Para Habermas, o Estado democrático não necessita de se fundamentar numa narrativa religiosa ou num referencial metafísico. O filósofo crê que a participação de todos no processo democrático garante a construção de ornamentos jurídicos baseados nos valores da razão pública. Mas este processo exige que os participantes aprendam a ver a realidade a partir do olhar do outro. Essa cultura da alteridade é essencial na construção dos consensos (Habermas 2009, 125-128).

No quadro da racionalidade comunicativa, pensada por Habermas, um e outro, o crente e o não crente, descobrem a necessidade de compreender as suas diferenças, e ambos participam, a partir dessas diferenças, na construção da esfera

\footnotetext{
5 Cf. Willaime, 2004, 229-258; Davie, 2000, 176-194; Hervieu-Léger, 1999, 201-252.

6 Estas reorientações distinguem-se, no entanto, das perspectivas de revisionismo teórico - entre as mais sonantes, conta-se a trajetória de Peter L. Berger (cf. Berger, 1999; Teixeira, 2003).
} 
pública. Como observa Habermas, o Estado constituído democraticamente não se limita a garantir as liberdades negativas a sujeitos sociais preocupados com o seu bem-estar. Facilitando os contextos favoráveis à concretização das liberdades comunicativas, mobiliza os cidadãos para o debate público a acerca do que thes diz respeito. Ora, como podem os cidadãos participar neste debate colocando entre parêntesis as suas mundividências, incluindo as que se declinam num sistema simbólico religioso? Tendo em conta os fundamentos das democracias liberais, como defender uma cidadania esquizofrénica, em que alguns cidadãos, no debate público, são convidados a colocar uma parte das suas convicções no limbo da impertinência social? Paradoxalmente, alguns dos símbolos da cidadania moderna, em particular no âmbito da defesa dos direitos cívicos - Martin Luther King ou Desmond Tutu -, participaram nessas lutas, mobilizando explicitamente as suas convicções religiosas (Habermas, 2009, 133-135).

Habermas vai mais longe, vendo nas tradições religiosas uma fonte possível de sabedoria, válida para a construção de consensos que vão para além do campo religioso, acerca da vida em comum, do que percebemos como mais ameaçante ou do que não encontra voz noutros modos de agir sobre o mundo (Habermas, 2009, 136-141). Neste contexto, reivindica a possibilidade de um agnosticismo aberto a novas aprendizagens. Assim, Habermas explora as vias de uma racionalidade aberta à crítica das práticas sociais com origem nas comunidades religiosas. No entanto, as religiões universais, assumindo os riscos de uma palavra pública, são estimuladas a procurar uma razão comum que promova a possibilidade de tradução da sua singularidade ultrapassando os riscos da sua própria exculturação. Como sublinhou Olivier Roy, no seu ensaio sobre a religião no contexto da mundialização contemporânea, é possível encontrar, entre os processos de reidentificação religiosa mais recentes, o mito da "santa ignorância» - a ficção de uma religião pura, fora das culturas. Este islamólogo vê nos revivalismos religiosos contemporâneos uma consequência da mundialização e destabilização das culturas. Este contexto cria condições favoráveis tanto para a exacerbação das diferenças, quanto para a estandardização das práticas (Roy, 2008). 


\section{Referências}

Bail, C. A. (2008). The Configuration of Symbolic Boundaries against Immigrants in Europe. American Sociological Review, 73, 27-59.

Beraud, Céline; Galembert, Claire de; \& Rostaing, Corinne. (2016). De la religion en prison. Rennes: Presses Universitaires de Rennes.

Berger, Peter L. (Dir.). (1999). The Desecularization of the World: Resurgent Religion and World Politics. Grand Rapids, MI: Eerdmans.

Blaquart, Jean-Luc. (2010). Religion et politique: les avatars du salut chrétien. In:

Baziou, Jean-Yves; Blaquart, Jean-Luc; e Bobineau, Olivier. Dieu et César, séparés pour coopérer? Paris: Desclée de Brouwer. P.55-67

Davie, Grace. (2000). Religion in Modern Europe: A Memory Mutates. Oxford, New York: Oxford University Press.

Dieckhoff, Alain. (1997). "Logiques religieuses et reconstruction démocratique." In Religion et Démocratie : nouveaux enjeux, nouvelles approches, Dir. Patrick Michel. Paris : Albin Michel, 317-338.

Donnet, Claire. (2013). Organisations musulmanes et pouvoirs locaux : concurrence et normalisation par l'islam civil à Strasbourg. In: Quand le religieux fait conflit : désaccords, négociations ou arrangements, Dir. Anne-Sophie Lamine. Rennes: Presses Universitaires de Rennes, 33-45.

Fath, Sébastien. (2013). L'affaire des minarets en Suisse et les réactions évangéliques. Approche comparé Suisse/France. In: Quand le religieux fait conflit : désaccords, négociations ou arrangements, Dir. Anne-Sophie Lamine. Rennes: Presses Universitaires de Rennes. p.161-171

Frégosi, Franck; \& Jean-Paul Willaime. (Dir). (2001). Le religieux dans la commune : Les régulations locales du pluralisme religieux en France. Genève : Labor et Fides.

Galembert, Claire de. (2003). La gestion publique de l'islam en France et en Allemagne. Revue Internationale et Stratégique, 52: 67-78.

Habermas, Jürgen. (1981). Theorie des kommunikativen Handels, I-II. Frankfurt a. M.: Suhrkamp.

(2009). Zwischen Naturalismus und Religion: Philosophische Aufsätze. Frankfurt a. M.: Suhrkamp.

Hervieu-Léger, Danièle. (1999). Le pèlerin et le converti : la religion en mouvement. Paris: Flammarion. 
(2001). La religion en miettes ou la question des sectes. Paris: Calmann-Lévy.

Hirschman, Albert O. (1994). Social Conflicts as Pillars of Democratic Market Society. Political Theory, 22: 203-218.

Lamine, Anne-Sophie. (2004). La cohabitation des Dieux : Pluralité religieuse et laïcité. Presses Universitaires de France.

(2013). Stratégies, différenciations et compromis : vers une grammaire de la conflictualité à dimension religieuse. In: Quand le religieux fait conflit : désaccords, négociations ou arrangements, Dir. Anne-Sophie Lamine. Rennes: Presses Universitaires de Rennes, 213-234.

Lorcerie, Françoise. (2013). Usages publics de l'islam en France : entre altérité et établissement. In: Quand le religieux fait conflit: désaccords, négociations ou arrangements, Dir. Anne-Sophie Lamine. Rennes : Presses Universitaires de Rennes, 15-32.

Mafra, Clara. (2002). Na posse da palavra: religião conversão e liberdade. Lisboa: ICS.

Mapril, José. (2012). Islão e transnacionalismo: uma etnografia entre Portugal e o Bangladeche. Lisboa: ICS.

Michel, Patrick.(1994). Politique et religion : la grande mutation. Paris: Albin Michel.

Pace, Enzo. (1997). Logos versus demos. In: Religion et Démocratie : nouveaux enjeux, nouvelles approches, Dir. Patrick Michel. Paris: Albin Michel, 339-360.

Roy, Olivier. (2008). La sainte ignorance : le temps de la religion sans culture. Paris: Seuil.

Sarg, Rachel. (2013). La pluralité religieuse en milieu carcéral : ajustements et gestion des conflits. In: Quand le religieux fait conflit: désaccords, négociations ou arrangements, Dir. Anne-Sophie Lamine. Rennes : Presses Universitaires de Rennes, 63-76.

Teixeira, Alfredo. (2003). Berger versus Berger. O ocaso da religião ou o seu regresso à cidade secular? Theologica (2ª série), 38: 249-272.

Vivarelli, Clémentine. (2013). L'ambivalence des pratiques laïques en milieu scolaire : la régulation de l'islam visible. In: Lamine, Anne-Sophie. (Dir.). Quand le religieux fait conflit : désaccords, négociations ou arrangements. Rennes: Presses Universitaires de Rennes, 95-107.

Willaime, Jean-Paul. (2004). Europe et religions: les enjeux du XXIe siècle. Paris: Fayard. 
Manuscrito recebido em: 18 de outubro de 2020

Aprovado em: 08 de novembro de 2020

Publicado em: 10 de novembro de 2020 